\title{
56. Psychic Symptoms in Tumors in Chiasmal Region
}

\author{
Yutaka Makı, Takeshi Horie, Yoshitaka Nakada, Koki Kawamura, \\ Masaaki Kurithara and Susumu MineI \\ Dept. of Neuropsychiatry, School of Medicine, Chiba University
}

Eight cases of tumor in chiasmal region, initially treated as psychotic problems were reported. They consisted of five pituitary adenomas, two craniopharyngiomas and epidermoid. The occurrences of psychic manifestations during the whole course of the tumors were not so frequent as frequent as compared with those observed in the other regions. However, when the psychic symptoms were seen in this region, they usually appeared in the earlier stage and, as initial symptoms, showed high occurrence of $34.7 \%$ like those seen in the cases of temporal tumors.

As the details of the psychic manifestations, delusion and auditory hallucination bearing the ideas of persecution, were the prominent features and, on the other hand, disturbances of memory and volition were less frequent. In addition, these delusions and hallucinations, being without the process of the disorganization of the personality and with phasic recurrence and spontaneous remission, seemed somewhat different from those of schizophrenia.

Cases Initially Treated as Psychotic Problem

$\begin{array}{lll}\text { Schizophrenia } & 3 & \begin{array}{l}\text { Chromophobe adenoma (2) } \\ \text { Acidophilic adenoma (1) }\end{array} \\ \text { Manic psychosis } & 1 & \text { Chromophobe adenoma } \\ \text { Depressive psychosis } & 1 & \text { Acidophilic adenoma } \\ \text { General paresis } & 1 & \text { Craniopharyngioma } \\ \text { Hysteria } & 1 & \text { Epidermoid } \\ \text { Nervousness } & 1 & \text { Craniopharyngioma }\end{array}$

